in France (2013-2015). Participants were 954 drivers injured in a road crash. The main outcome measure was responsibility for the crash. Covariates were external distraction, working memory, selective attention, alcohol use, psychotropic drug use, and sleep deprivation.

Results A high working memory was associated with responsibility for a traffic crash (odds ratio 1.9, 95\% confidence interval 1.3 to 2.6). Regarding selective attention, the group displaying an hyper focus on stimuli was also associated with responsibility for a traffic crash (odds ratio 1.6, 95\% confidence interval 1.1 to 2.3).

Conclusions Contrary to our expectations unimpaired executive function variables were associated with responsibility for the crash. It is possible that a better level of executive functioning may be linked to a higher focus on internal stimuli thus limiting attention to external and road stimuli.

\section{THE IMPACT OF MIND WANDERING ON ROAD SAFETY}

${ }^{1,2}$ Cédric Galéra, ${ }^{1}$ Cédric Gil-Jardinet, ${ }^{1,2}$ Mélanie Née, 1,2Rachid Salmi, 1,2Ludivine Orriols, 1,2Benjamin Contrand, ${ }^{1,2}$ Emmanuel Lagarde. ' University of Bordeaux, France; ${ }^{2}$ INSERM U897, France

\subsection{6/injuryprev-2016-042156.765}

Background Mind wandering before the crash has been associated with a heightened probability of being responsible for a crash. Yet measurement bias (desirability bias) may explain this association. To progress in the understanding of mind wandering in road safety we sought to assess the relationship between mind wandering trait (a persistent characteristic of the individual) and state (just before the crash) and the risk of being responsible for a road crash.

Methods We conducted a responsibility case-control study in an adult emergency department of the Bordeaux university hospital in France, (2013-2015). Participants were 954 drivers injured in a road crash. Measures were responsibility for the crash, mind wandering (trait/state), external distraction, alcohol use, psychotropic drug use, and sleep deprivation.

Results Intense mind wandering (highly disrupting/distracting content) state was associated with responsibility for a traffic crash (odds ratio 2.3, 95\% confidence interval 1.5 to 3.5). Mind wandering trait was also associated with responsibility for a traffic crash (odds ratio 1.8, 95\% confidence interval 1.3 to 2.5 ).

Conclusions Mind wandering, whether just before the crash or as a general propensity characteristic of the individual, is associated with a higher risk of being responsible for crashes. Mind wandering is a deleterious source of inattention on the road.

\section{IMPLICATIONS OF MARKING REGIONAL AND GLOBAL ROAD SAFETY EVENTS 2014-2015 ON MULTISECTORAL COLLABORATION IN QATAR}

Hassan Al-Thani, Rania Abdelhamid, Monira Mollazehi. Trauma Surgery, Hamad General Hospital, Qatar

\subsection{6/injuryprev-2016-042156.766}

Background Marking of the global and sub-regional road safety events at the national level is one of the recommendations of the Global Plan for the Decade of Action for Road Safety 20112020 to increase the awareness of risk factors and the need for enhanced road traffic injury prevention. Examples of the Global events are the United Nations Global Road Safety Weeks and the
World Remembrance Day for Road Traffic Victims and Subregional road safety event are the Gulf Countries Corporation Traffic Weeks held every year during March.

Objective To examine the implication of marking the global and sub-regional road safety events during 2015 on the road safety awareness agenda in Qatar.

Results The World Remembrance Day for Road Victims was marked in Qatar in the 3rd Sunday of November 2014 by multiple national sectors and demonstrated commitment. Following the event, an in-depth evaluation of the stakeholders needs was done by the awareness section of the Traffic Department and Hamad Injury Prevention Program- Trauma Surgery, Hamad General Hospital and concluded that road safety awareness require a systematic and multi-sectoral collaborative approach. This internal evaluation resulted into a substantial improvement of the collaboration between both sectors, starting from the participation in the $31^{\text {st }}$ Gulf Countries Corporation Traffic Week in March 2015 with several participatory activities by Hamad Injury Prevention Program. Another internal evaluation was conducted following the Gulf Traffic Week to identify progress and needed actions. In May 2015, a more collaborative activity for the $3^{\text {rd }}$ United Nations Global Road Safety Week with emphasised planning using the recommendations of the former events and with involving more sectors such as the Supreme Council of Education and Non-Governmental Organisations. The evaluation of the global event acknowledged that the quality and efficiency of the awareness activities in Qatar was improved by multi-sectoral collaboration and recommended joint planned awareness activities on routine basis.

Conclusions Marking the Global and Sub-regional road safety events emphasised the positive impact of the multi-sectoral collaboration in a systematic way to improve the road safety awareness and guided the national stakeholders in Qatar for future and directed collaborative activities.

\section{Occupational Safety}

\section{Post Tue 2.17}

\section{MUSCULOSKELETAL DISORDERS AND ITS CORRELATES AMONG FARMERS WORKING ON VEGETABLE GREENHOUSE}

Hongyan Yao, Jianjun Liu, Wenjing Zheng. Chinese Centre for Disease Control and Prevention

\subsection{6/injuryprev-2016-042156.767}

Background This study aims to examine the incidence of musculoskeletal disorders (MSDs) among farmers woring on vegetable greenhouse and to identify the potential correlates of musculoskeletal disorders.

Methods A total of 1823 farmers worink on vegetable greenhouse from 15 villages of five main vegetable growing areas in Shouguang city of Shandong province were interviewed using a modified household questionnaire. Chi-square test was performed to assess the incidence of MSDs across farmers with different greenhouses and multivariate logistic regression was performed to explore its risk and protective factors.

Results Among the valid 1780 subjects, 1395 (78.4\%) cases reported that they had the experience of MSDs during the past 12 months. The top four positions with MSDs were low back (62.4\%), knee(s) (41.9\%), neck (22.9\%), and shoulder(s) 